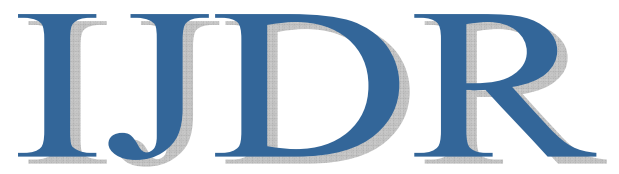

International Journal of Development Research

Vol. 10, Issue, 06, pp. 36426-36430, June, 2020

https://doi.org/10.37118/ijdr.18957.06.2020

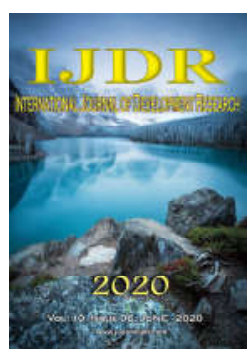

\title{
IOT APPLIED TO WORK SAFETY IN INDUSTRY 4.0 AT THE AMAZONAS INDUSTRIAL POLE
}

\section{Maurisergio Ferreira de Aquino Filho, ${ }^{1}$ Jean Mark Lobo de Oliveira and *2David Barbosa de Alencar}

\author{
${ }^{1}$ Academic department, University Center FAMETRO, Amazon-Brazil \\ 2Institute of Technology and Education Galileo of Amazon (ITEGAM), Brazil
}

\begin{abstract}
ARTICLE INFO
\section{Article History:}

Received $11^{\text {th }}$ March, 2020

Received in revised form

$21^{\text {st }}$ April, 2020

Accepted $08^{\text {th }}$ May, 2020

Published online $25^{\text {th }}$ June, 2020

Key Words:

IoT; Industry 4.0; Amazon Industrial Pole.

*Corresponding author: David Barbosa de Alencar,

ABSTRACT

The study aims to find out factors The Internet of Things (IoT) approach - is a technology that is reconfiguring the sectors of activity, changing the definitions of how objects are connected to each other, today it is being applied in companies and industries, transforming the scenario how companies compete, changing the business models, structure and process of organizations. The following article aims to conceptualize IoT, work safety, industry 4.0 and analyze how these applications are implemented in companies in the industrial pole of Amazonas. We sought to understand and identify through the concepts the challenges and impacts on companies and industries. With the advancement of new technologies, the Internet of Things has been transforming and changing showing that companies are investing in different smart technologies, that is, IoT has become one of the pillars of industry 4.0, bringing modernity, security and optimization of the manufacturing of industries as quick data analysis, production decision making and cost reduction. At the end of the elaboration of this work, it was observed that the chosen theme is of great importance mainly in the transition of new technologies, security and information. A bibliographic search was made, with references and information able to form a more comprehensive analysis on the topic.
\end{abstract}

Copyright (C) 2020, Maurisergio Ferreira de Aquino Filho. This is an open access article distributed under the Creative Commons Attribution License, which permits unrestricted use, distribution, and reproduction in any medium, provided the original work is properly cited.

Citation: Maurisergio Ferreira de Aquino Filho, Jean Mark Lobo de Oliveira and David Barbosa de Alenca. "IoT applied to work safety in industry 4.0 at the amazonas industrial pole", International Journal of Development Research, 10, (06), 36426-36430.

\section{INTRODUCTION}

Of fundamental importance, Industry 4.0, also known as the Fourth Industrial Revolution, is increasingly presenting a new concept of production. Through the use of digital technologies, supported on the Internet. With the industrial environment closely following these developments, it is shaping itself for Industry 4.0 using the Internet as a vehicle for exchanging information, an immeasurable number of devices can be connected, exchanging information in real time, which is now called the Internet of Things (CNI, 2016). According to Klaus Schwab, it is common knowledge that Industry 4.0 currently brings together automation and information technology, in addition to the main technological innovations in these fields, it is a set of technologies that allow the union of the physical, digital and biological world. In this respect, the Internet of things (IoT) opens up conditions for industries, if they make better processes with better products. So Iot is happening for what it can provide, such as, more resources in work safety or better adjust and adapt information security, since the Internet of Things will help a company to achieve efficiencies, harness the intelligence of a wide variety of equipment, improve operations and increase customer satisfaction. As the Internet has the fundamental role for this connection, since every industrial environment is subject to risks. It can be said that, due to information security, professionals in the technology area are concerned with concern. Security issues should always be treated with careful risk analysis and application of frameworks that involve, in addition to information security, the security of production processes, whether electronic or not. Everyone knows that, in Brazil, the importance of the Industrial Revolution has been discussed for some time, we are currently discussing the fourth industrial revolution 4.0, a new reality with several markets around the world, the factory becomes agile with this new model of industry 4.0. Evidently we have factories that do not follow this evolution, some of these factories are in the industrial pole of Manaus. These changes will have impacts applied to work safety. The purpose of this article is to analyze the Internet of Things, based on the 
application to work safety in Industry 4.0 in the industrial pole of Manaus. As it is a current topic, there are some doubts and questions that need to be resolved. This article will help you to understand more about the subject. We explain some concepts, show the history of these changes, how they are applied and what challenges you will need to overcome.

\section{BIBLIOGRAPHIC REFERENCE}

Currently, it is observed that each industrial revolution presented technological innovations in its time, due to the countries building improvement and technological solutions. As a consequence, it is observed that there are new opportunities and challenges for companies and states. Thus, it opens the way for transformations in the productive world in the face of these innovations, Brazil found it difficult to keep up with these innovations. Faced with these new changes, Amazonas is not prepared for this challenge, as they demand technological knowledge and work safety.

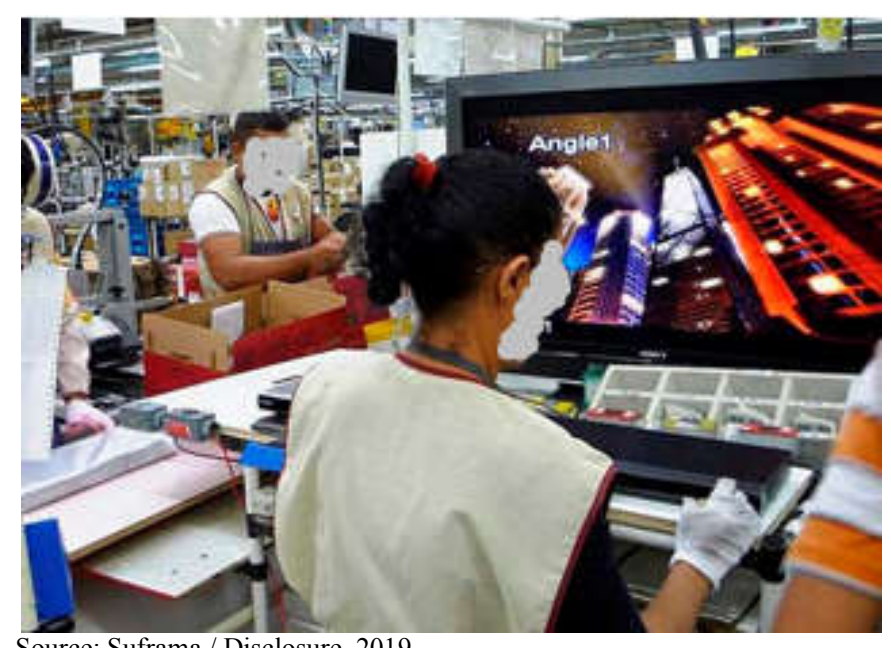

Source: Suframa / Disclosure, 2019.

Fig. 1. Production process representation

\section{IOT - Internet of Things}

The term IoT was introduced in 1999 by British technology expert Kevin Ashton in his talk at Procter \& Gamble (P\&G). However, the thinking regarding IoT had already started before, in the publication of an article by Alan Turing, in the year 1950, where it brought the following theme: "can machines think?". The diversity of Internet of Things (IoT) applications has revolutionized the way we relate to technology, allowing objects and mechanisms to be detected in the middle of production and distribution by infra network mechanisms, ensuring greater security and management control for companies. According to Bagheri (2015), IoT is responsible for collecting information in the physical space, connecting several products to each other, unlike Cyber Physical Systems that uses clouds and mechanisms and sensors to adjust something physical to a certain projected state. For Liu and Xun (2017), the Internet of Things represents more than a mechanism of interconnection between the natural and the virtual environment, being highlighted by the authors the agility through remote control among the products, which can provide greater optimization in the productive processes of an organization. IoT has been applied in work environments with several purposes, from using it to increase your earnings in a matter of time, to cybersecurity as security of physical work.
According to studies by authors, the concept of the internet of things comes from digital interconnection, thinking more deeply, it would be like a new internet, with interconnectedness in everyday objects. In the year 2018 there was an article in the magazine Cipa, where it addressed the following title "IoT solutions are used to prevent accidents", citing in its text that "Brazil is the fourth country with the highest number of deaths due to accidents at work" International Labor Organization (ILO). The use of the internet of things in the workplace to prevent accidents is already used today, the use of sensors to control machines and movements, the connectivity of various machines, all aiming to prevent accidents.

Workplace Safety: The role of Occupational Safety in Industry makes it necessary to ensure the protection of operations as a whole. It is the science that studies the possible causes of accidents and incidents that may happen to the worker during his work activity, its main objective is to prevent future occupational diseases, accidents and any future forms that may aggravate the worker's health. Work safety in Brazil until 1988 when it was enacted in the federal constitution, is always seen by the employer as a necessity for its employee, in its structure federal, state and municipal laws were created. It is of fundamental importance the application occupational safety in large, medium and small organizations, is an extremely important point due to accident prevention, the occupational safety professional must strictly obey the international conventions that deal with the subject and value them and observe that in current times major changes in conception of products, processes and technologies affect the most diverse areas of knowledge.

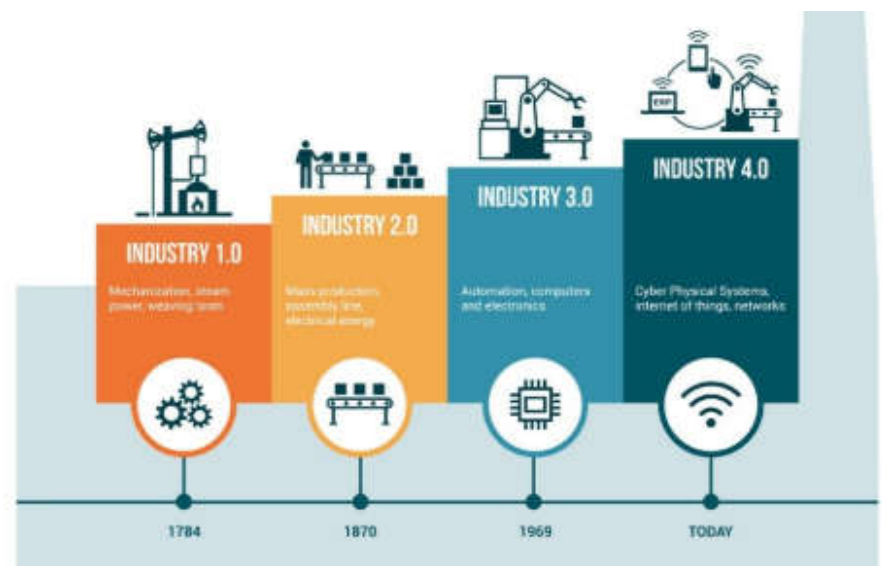

Source: Endeador, 2018

Fig. 2. Representation of the stages: Industrial Evolution

It is important to point out that in industry 4.0, the control of robots and automated machines can bring a risk to the worker in the control of these machines, the risk to which workers are exposed during the working day, however these machines are not only the focus of intelligence artificial. Preventive measures are evident in the work of the employee, it does not only involve eliminating physical risks, with a very efficient technological infrastructure, professionals perform more appropriate activities, in an environment where there is not much stress. Not to mention the benefits that technological advances can bring to companies and employees and it is up to us Determinism to do everything possible so that Work Safety goes hand in hand with innovations. Thus, job security and care for the emotional state must be a constant concern of managers. Therefore, it is necessary to know all aspects, 
positive and negative, of industry 4.0 and make the necessary adjustments to your company. Safety and well-being of employees are a constant concern of managers and entrepreneurs. Therefore, fighting its causes has become part of the natural routine of any company. Industry 4.0 , in turn, it has shown us innovative and more effective ways of acting preventively.

Industry 4.0: Known as the fourth industrial revolution, Industry 4.0 emerged with the increasing automation of production processes, together with the technological advancement of the internet and the development of intelligent objects. The fourth industrial revolution, which will have a deeper and exponential impact, is characterized by a set of technologies that allow the fusion of the physical, digital and biological world. According to Hermann (2015), industry 4.0 can be understood as a German term, in which it designates a collective concept of smart technologies and factories in the face of process monitoring. Lu (2017), on the other hand, industry 4.0 can be understood as a relevant process, marked by the automation of digitization processes and the use of Information Technology tools to manufacture products and services. According to Hofmann and Rusch (2017), the definitions presented above can only be considered by organizations when they individually define what industry 4.0 means for them. From this, companies are able to apply the processes defined as part of industry 4.0 and as a consequence benefit from their respective uses in their commercial activities. In view of the above, industry 4.0 presents solutions to raise the level of market competitiveness, because the stagnation in the industrial sector is directly related to the reduction in the general quality of life of society.

Manaus Industrial Pole: Brazil has been growing every year, with this new industries are implemented so we have the growth in new technologies that have been changing the World market. Therefore, the Manaus Industrial Pole is recognized as being of great importance for the development of the state. In fact, with industry 4.0, companies began the transition in their digital transformation processes considering their reality, such as the development of workers, the sharing of knowledge and the use of new technologies. The image below shows how manufacturing 4.0 works that inserts connectivity, data flow in the factories.

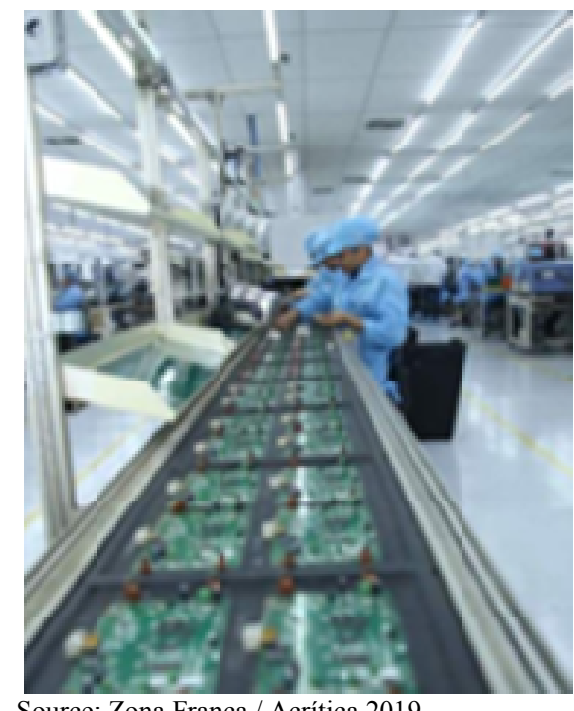

Source: Zona Franca / Acrítica 2019

Fig. 3. Representation of the automated process inside the Industry in Manaus
As duly exposed by the publication by (Jornal Acrítica, 2019) whether the Amazon has been growing along with this development, the industrial market since its implementation in the early 90s to the present day, the Amazon region is a state that is growing every year that passes, so the industrial hubs of adding a lot in relation to industry 4.0. Manaus being the capital of the state of amazonas today it has been showing its development in the industry, Elsys Eletrônicos is an example in the branch of industry 4.0, which from 1990 to the present day has been showing this growth, with strong and versatile investment, has boosted the production of a flexible way that will sustain industry 4.0 .

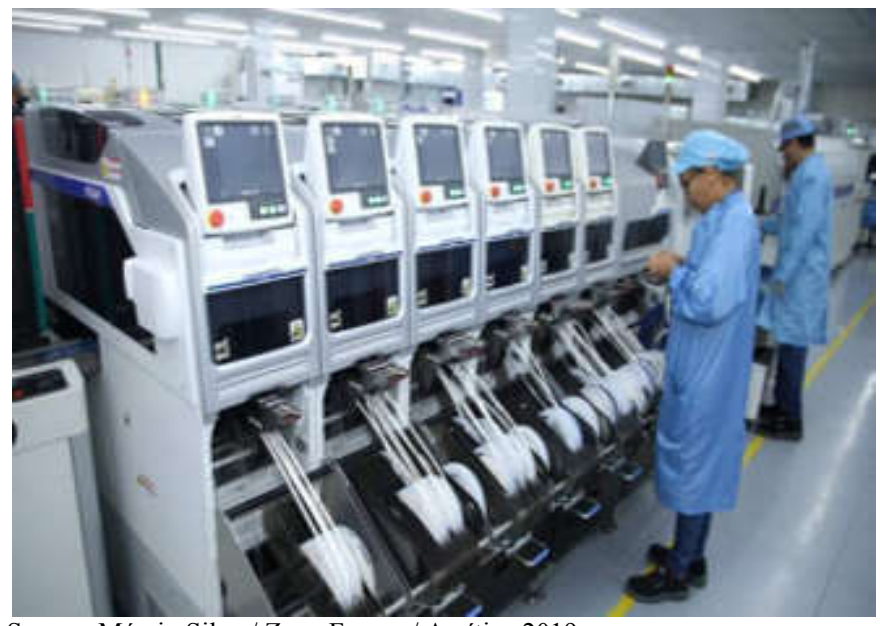

Source: Márcio Silva / Zona Franca / Acrítica 2019

Fig. 4. Representation of process control services

Therefore, the main objective was to help companies that, with new technologies, productive resources would be effective in production, thus seeing the development of an industry will bring news to the growth of the country, optimizing the production lines, bringing the benefit of monopolizing the novelties that technologies will favor for growth.

\section{MATERIALS AND METHODS}

The methodology used in this article was a bibliographic search, in which articles, magazines, books and materials were presented that present knowledge about Internet of things - Iot, Industry 4.0, work safety, industrial pole of Amazonas. The focus of the article was concentrated on the use of technologies in industrial systems; mainly focused on the application between Iot - internet of things and artificial intelligence, it has optimized the processes in the factories. Since, they were used to give an understanding. Industry 4.0 books, IoT, were also used to understand the current scenario of companies in the industrial pole of Amazonas. In addition, a quantitative survey was conducted, applying a questionnaire of $\mathrm{X}$ closed questions, with only one answer, through the Google platform Forms, the questionnaire responses were obtained through social networks, such as: WhatsApp.

\section{DISCURSION AND RESULT}

Aware of the importance of the Fourth Industrial Revolution in the reality of companies in Amazonas, a survey was conducted identifying the degree of knowledge about the concept and the impacts of Industry 4.0. As the discussion on the topic is recent in Brazil, one of the research concerns was to identify the level of knowledge of the participants. 
According to the survey, $87.5 \%$ of respondents answered yes and only $12.5 \%$ said they do not know what industry 4.0 is. This result is shown in figure 1. This highlights the issue of new technologies present in industries, in which participants may have little or no contact with this technological evolution.

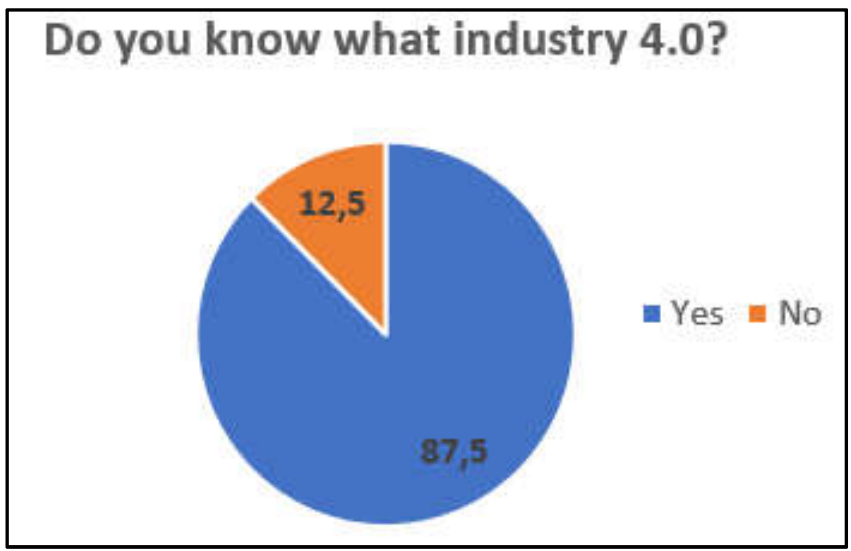

Source: The Authors, 2020.

\section{Graph 1. Graph of the percentage of knowledge level about Industry 4.0}

Another aspect that deserves an analysis is the assessment of the level of knowledge related to Digital Skill, with $56.3 \%$ of respondents considering themselves at the medium level, that is, it is easy to learn new technologies. As shown in figure 6 . Maybe some people haven't noticed yet, but we are already living in the digital age. New technologies are increasingly present in our lives, whether in the private, public and / or professional context. This means that, in general, everyone must remain in a constant process of learning and change, as technologies evolve rapidly and new trends are always launched.

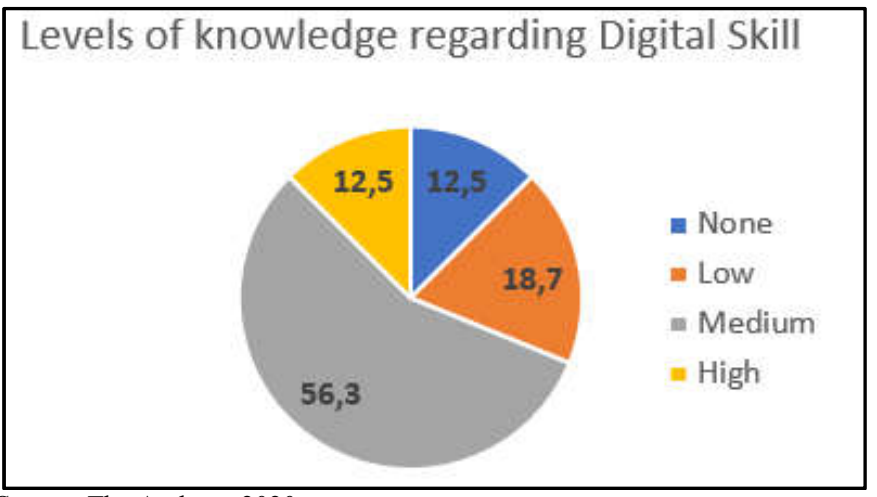

Source: The Authors, 2020.

\section{Graph 2. Percentage of knowledge levels regarding Digital Skill}

It is a fact that technologies and their innovations are advancing in a short time and often not well assimilated, requiring viable preparation, studies and projects that make it possible to face changes in the digital and knowledge society. Industry 4.0 is marked by data automation and the use of the cloud to store information, leading production processes to stay connected and providing greater productivity and much more efficient management. According to research carried out, on the changes that occur in a company when it adopts industry $4.0,40 \%$ mention the ease of access with the new technologies, $60 \%$ comment on Information Security and 20\% on data storage. It is undeniable that this digital transformation in the industry has promoted many benefits - we can also mention greater performance, competitiveness and agility, more effective communication and cost reduction. Graph 3 below shows some of the changes that Industry 4.0 offers to a company.

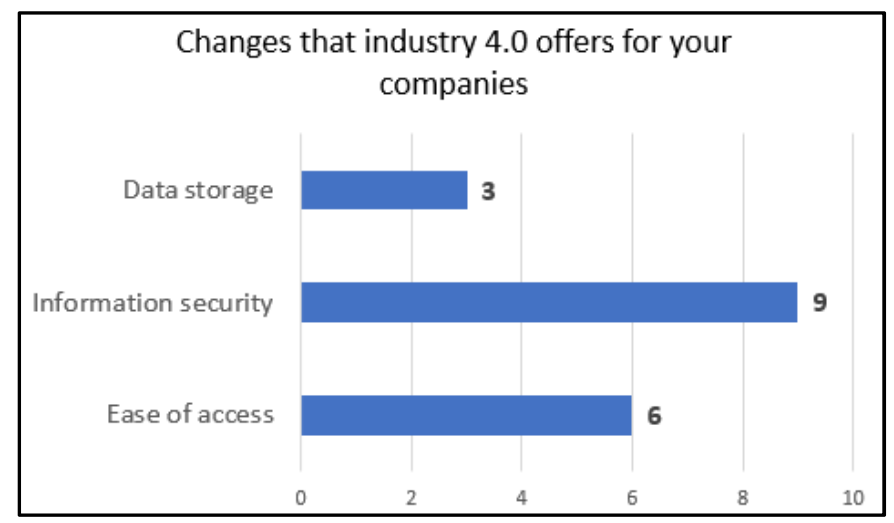

Source: The Authors, 2020

\section{Graph 3. Changes that industry 4.0 offers for companies}

In order to carry out this work, some questions related to the theme were elaborated, one of them was related to the technology used in the company related to industry 4.0 , in terms of the results, there was a great use of IoT and cloud technology, meaning that companies are using the internet of things a lot in its activities, both for security, as for time and quality of production and also the use of cloud technology to have greater security of backups and agility in processes.

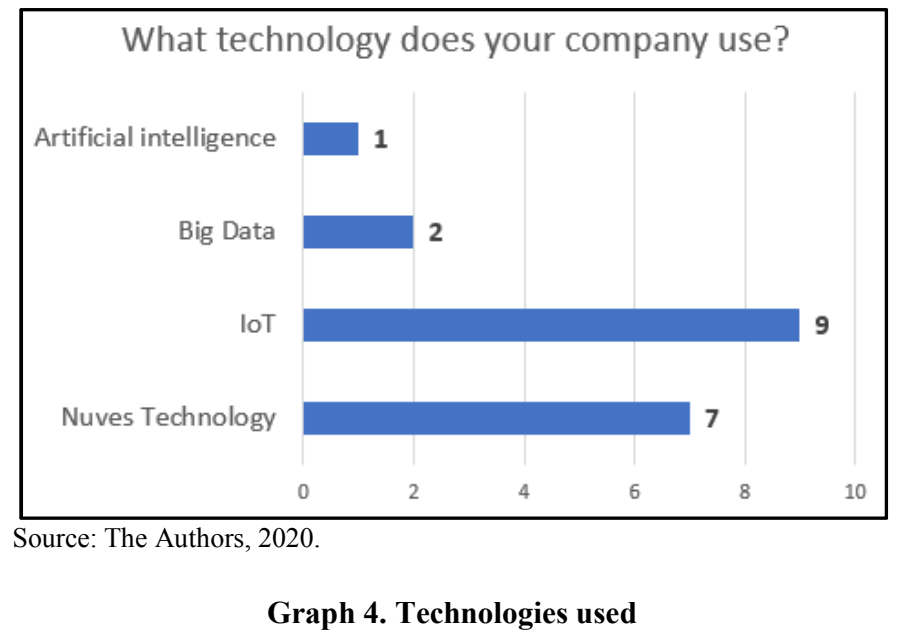

The development of industry 4.0 in Amazonas involves challenges and impacts that range from investments in labor and equipment that incorporate these technologies, ie adaptation of layouts and processes, that is, the creation of new specialties and the development of skills. On the other hand, these new changes require a challenge for the factories, such as the implementation of new automated processes, training to work, since few qualified professionals and specialized in technologies.

Today, these changes are necessary. In addition, many employees are easy to learn, but are not prepared for these changes. Regarding industry 4.0, when the company where you work / acted started to adopt industry 4.0 when having to learn some new technology. As you can see the result of the research that is very easy to learn $(62.5 \%)$, others have difficulty learning / using (31.3\%), did not have to learn anything $(6.3 \%)$. 


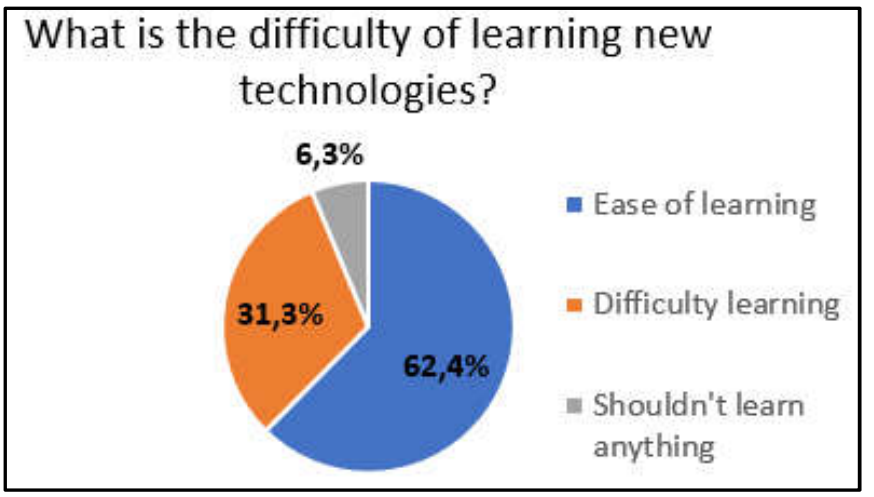

Source: The Authors, 2020.

\section{Graph 5. Learning new technologies}

In view of this result, we can affirm that the implantation of industry 4.0 is a great challenge for the companies and managers of the Industrial pole of Amazonas, one of these challenges is the lack of specialized labor. We would say that it doesn't need to take a long time to deploy, what you really need is people with the capacity and condition to interact with these machines. Therefore, the use of data is, in itself, a field of vast opportunity to improve the efficiency of the industry.

\section{Conclusion}

The present article allows us to conclude that the Internet of Things is extremely important for the development of companies in the Industrial Pole of Amazonas. The ability to work collaboratively is a foundation of this new industry, whose keyword is connection. Therefore, the choice of the appropriate technology cannot be a failure, to ensure that they are aligned with your objectives, thus correctly supporting the benefits adhering to your business. Cloud computing, Internet of things and Big Data are basic technologies, being the means of all operation and application of improvements and new technologies created in Industry 4.0 The path to the broad implementation of the technologies that make up the concept of Industry 4.0, taking advantage of everything it has to offer is still long. Most companies can be expected to introduce their elements gradually, based on new solutions, without jeopardizing financial and industrial stability. Finally, due to many paradigm changes throughout the evolution of the goods and services industry, the integration between IoT and Industry 4.0 already allows creating opportunities for cities that are more efficient and with less energy and waste consumption.

The adoption of the internet of things (IoT) in the industrial environment has become an extremely important point, optimization, practicality and modernity in the way of producing the products and services in which each industry is specialized, taking into account the current scenario is essential that each industry has IoT implemented in its structure.

The constant transition to the fourth industrial revolution or industry 4.0, showed itself and presented significant and radical changes in the way of producing and in the way of professionalizing its professionals to new technologies adopted in the new industrial environment, whether they are small, medium or large, in this transition from what is happening in the industrial environment. The Industrial Pole of Manaus Amazonas is presented in large companies with a little bit of production automation using intelligent systems, but not fully implemented in the company, however the identification of industry 4.0 characteristics is noteworthy, so it is clear that the application of strategies and implementation of resources, even if it is arduous, it is possible that with this it is possible to improve all manufacturing sectors of companies, always following the concepts of work safety for their employees.

\section{Acknowledgments}

I thank God first for keeping me on the right track during this research project with health and strength to reach the end.

I am grateful to my family for the support they have always given me throughout my life. I would like to give a special thanks to my advisor. for the encouragement and dedication of his limitedtime to my research project.

\section{REFERENCES}

BAGHERI, B. Cyber-physical systems architecture for selfaware machines in industry 4.0 environment. IFACPapersOnLine, v. 48, n. 3, p. 1622-1627, 2015.

BARSANO, Paulo Roberto. Segurança do trabalho: Guia prático e didático/Paulo Roberto Barsano, Rildo Pereira 2. ed. São Paulo: Saraiva/Érica, 2018.

CONFEDERAÇÃO NACIONAL DA INDÚSTRIA - CNI. Desafios para indústria 4.0 no Brasil. Brasília: CNI, 2016.

FLÁVIA, Ana. Soluções de IoT são utilizadas prevenção de acidentes. Cipa.14 de novembro de 2018. Disponível:< https://revistacipa.com.br/solucoes-de-iot-sao-utilizadasna-prevencao-de-acidentes/>. Acessado em 14 maio 2020.

GRILLETTI, Laís. Indústria 4.0: as oportunidades de negócio de uma revolução que está em curso. Endeador. 10 de agosto, 2017/Atualizado em: 29 de março, 2018. Disponível em: < https://endeavor.org.br/ tecnologia/industria-4-0-oportunidades-de-negocio-deuma-revolucao-que-esta-em-curso/: Acessado em 15 maio 2020.

GUIMARÃES, Cinthia. Por dentro da Industria $4.0 \mathrm{em}$ Manaus. Acrítica. Com. 29 de Setembro de 2019. Disponível em: <https:/www.acritica.com/channels/ dinheiro/news/por-dentro-da-industria-4-0-em-manaus $>$. Acessado em 15 de maio 2020.

HERMANN, M.; PENTEK, T.; OTTO, B. Design principles for Industrie 4.0 Scenarios: a literature review. Working Paper. n.01/2015, TechnischeUniversitat Dortmund, 15p, 2015.

HOFMANN, E.; RÜSCH, M. Industry 4.0 and the current status as well as future prospects on logistics. Computers in Industry, v. 89, p. 23-34, 2017.

LIU, Y.; XU, X. Industry 4.0 and cloud manufacturing: A comparative analysis. Journal of Manufacturing Science and Engineering, v. 139, n. 3, p. 034701, 2017.

LU, Y. Industry 4.0: a survey on technologies, applications and open research issues. Journal ofIndustrial Information Integration, v. 6, p. 1-10, 2017.

SCHWAB, Klaus Schwab - A Quarta Revolução Industrial. São Paulo: Edipro, 2016. ISBN: 9788572839785

Turing, Alan (October 1950), Computing Machinery and Intelligence, Mind, LIX (236): 433-460

VENTURA, Iolanda. Industria 4.0 em Manaus esbarra na falta de investimento e trabalhador especializado. Amazonas Atual. 10 de novembro de 2019 no > Economia. Disponível em: < https://amazonasatual.com.br/industria4-0-em-manaus-esbarra-na-falta-de-investimento-etrabalhador-especializado/: Acessado em 16 maio 2020. 